\title{
The contribution of G. W. Leibniz's 'cognitio symbolica' theory to current debates on knowledge and communication management ${ }^{\star}$
}

DIANA INGENHOFF

\section{Abstract}

The aim of this paper is to clarify the concepts of knowledge to develop a better theoretical understanding based on one of the eldest semiotic insights from one unfortunately often forgotten philosopher of modern semiotic: Gottfried Wilhelm Leibniz (1646-1716). In his 'Meditationes de Cognitione, Veritate, et Ideis' (1684), he develops a systematical, dichotomous characterization of the different levels of knowledge acquisitions. According to his view, knowledge is essentially symbolic: it takes place in a system of representations which possesses language-like structures and which can be characterized on specific hierarchic levels from 'dark knowledge' ('notio obscura') up to 'distinct knowledge' ('notio distincta') to be distinguished by the criteria of recognizing and communicating the single elements ('notarum notae') constructing knowledge as a continuum.

From a semiotic point of view, the paper shows that the awareness of the hierarchy of knowledge intensity can supply a framework for conceptual analysis and modeling of knowledge creation processes. As a result, we actually should focus, not only in knowledge management, on the communication processes when creating knowledge. Leibniz shows the fundamental problem of decomposing knowledge in externalization processes, which is only possible by the use of symbols, needing clear explanations through symbols again. Therefore, organization should be concerned with the creation of shared representations and meaning systems with respect to different levels of explicitly as Leibniz showed us.

Keywords: cognitio symbolica; cognition; knowledge management; knowledge creation; knowledge communication; knowledge hierarchy. 
In the new economy, conversations are the most important form of work. Conversations are the way knowledge workers discover what they know, share it with their colleagues, and in the process create new knowledge for the organization

— Webber (1993: 28)

\section{Introduction}

For several years now, knowledge management seems to have promised a concept by which the most valuable resource of an enterprise, the human knowledge of its employees, can be captured and stored. The main focus within different kinds of such concepts is put on information technologies and documents stored therein (Pfeffer and Sutton 1999). What has still been missing until now in the debate on knowledge, information, and their manageability is a fundamental reflection upon some basic approaches of what is meant by communication process at all, recognized as the critical point in knowledge creation and transfer. Another reason for this development might be seen in a lack of understanding of the nature of knowledge and the underlying processes of knowledge externalization and transfer via communication (More 1998; Nonaka 1998; von Krogh et al. 2000).

However, according to different theoretical approaches, various models exist that attempt to explain the complex phenomenon, e.g., system theory approaches (Luhmann 1991), information theory approaches (Shannon and Weaver 1949) or constructivism theory approaches (e.g., Maturana and Varela 1992; Steffe and Thompson 2000). If we define communication in terms of intentional interaction by means of signs between at least two individuals (cf. Ungeheuer 1990), i.e., the fundamental condition of communication as a process of semiosis ${ }^{1}$ including the involvement of a communicator, a sign, and a recipient or interpreter of the sign, one fruitful approach might be the general theory of signs: Semiotics. Taking the underlying differentiation between the three entities of data, information, and knowledge in knowledge management concepts seriously, we have to rethink the common externalizable, positivistic, and technocratic view of knowledge as being codified in artifacts, representing an accurate copy of the knowledge in people's mind. By taking a critical distance towards taken-for-granted theories on knowledge and management imagined as explicit, storable, and controllable, this approach tries to rethink the concept of knowledge from an unaccustomed but inventive perspective: the idea of knowledge represented and constructed by signs according to 
Leibniz's theory of knowledge. Some aspects of this view are indicated in modern knowledge management concepts when Nonaka and Takeuchi (1995) define knowledge as symbolic representations of objects and links between objects, but without specifying further consequences.

This semiotic approach from one of the founding fathers of modern semiotic concepts created in 1684 could provide a framework for modern conceptual analysis of information and knowledge by pointing out the relation to communication. In this way, knowledge is not regarded as an entity, but as a semiotic construct.

In fact, while we can apply the archaic meaning of 'information' as 'formation,' derived from the Latin word 'forma' and the Greek word 'morphe,' information (in contradiction to knowledge) could be just transmission of 'forms' without 'contents.' Knowledge cannot be mere form, but there has to be some form or shape linked with some semantic content: a form stands for something else. The token standing for something else is normally called a sign. This way knowledge could be considered as a semiotic sign. One of the founding fathers and seminal thinkers of semiotics, Charles S. Peirce, defined a sign as

... something which stands to somebody for something in some respect or capacity. It addresses somebody, that is, creates in the mind of that person an equivalent sign, or perhaps a more developed sign. That sign which it creates I call the interpretant of the first sign. The sign stands for something, its object. (CP: 2.228)

In essence we create our knowledge by creating signs as we interact with objects in our environment. Thus there must be a subject who is able to interpret something to represent something else. Therefore, knowledge also needs an understanding subject with interpretative abilities, transforming mental activities of representations. In other words, knowing is a fundamentally human act (McDermott 1999) which is mediated through signs. It can never be isomorphoric with the objects of the world.

In Leibniz's terms, the mental activity can be described as 'cognition.' In our terminology, we would refer to the process leading to "knowledge acquisition.' As we will see, Leibniz's theory of knowledge applies the principle of continuity to the theory of perception, reflecting a hierarchy of knowledge intensity. As a result, he differentiates between least perfect perceptions of whose occurrence we are not conscious, to the most perfect perceptions that are endowed with reflective power and acts of reflection on all of the objects which constitute the perception.

The awareness of the hierarchy of knowledge intensity can supply a framework for conceptual analysis and modeling of knowledge management processes. If we refer to knowledge as a process of semiosis, and 
semiosis as an ongoing process of cognition and interpretation of signs, we have to take into consideration the limitations of knowledge explications and externalizations. In the process of knowledge communication we interact with each other by use of symbols. According to Leibniz, the meanings of these used symbols often remain implicit and 'dark' because of one fundamental problem: symbols can only be explicated by other symbols. While communicating, we often assume others' understanding of our signs and proceed until a misunderstanding becomes obvious. One of the reasons for communication failure therefore can be seen in the missing or belated explication of meanings, the missing embedding into another's context. The same problem occurs when knowledge is to be transferred or stored into databases. Often what is left are data without context, which are difficult or even impossible to understand and use.

As a result, in knowledge management we actually should focus on the communication processes between people rather than on knowledge or even storage technologies directly. It is important to note that the knowledge management organization should be concerned with what Jakobson (1960) refers to as shared meaning systems with respect to different levels of explicity as Leibniz showed us. At the most obvious level, this refers to a common language or definitions of terms that must be shared by the communicators (Meredith and Burstein 2000).

Therefore, this paper will give some insights into the current state of the art in knowledge communication issues. First, I will show that it might be fruitful to connect communication issues with knowledge management approaches in general. In the following section, I will present one example: I will give a short reflection of Leibniz's theory of knowledge and his connection to communication and signs as an explanation in the field of semiotics. Since this paper can only give a first insight into a semiotic approach, Leibniz's theory is chosen among the vast field of semiotic theories to serve as the classical example of how the sign can be considered as a knowledge representation. As we will see in the last section, these insights may contribute to a semiotic understanding of knowledge transfer and creation processes. By doing so, it may form a basis for further developments of theoretical assumptions and practical insights.

\section{First insights into the state of the art in knowledge communication issues}

Until now there has been little in the literature explicitly linking communication to knowledge management (More 1998; Etzioni and Etzioni 
1999; Von Krogh et al. 2000; Wilkesmann 2000), although the topic seems to have the potential of becoming a significant issue in the knowledge management debate in particular and in communications management in general. Communication plays an important role in the efficient and effective transfer of experiences, insights, and know-how. It serves as a prerequisite for coordinated, organizational action and decision making (Straub and Karahanna 1998), but above all for the co-construction of knowledge.

One of the main challenges of knowledge management will be the transfer of knowledge to stakeholders like customers and employees via communication. An example for this development is illustrated by Schmid (2001). He demonstrated that for the customer perspective, it follows that the design of a product cannot be realized successfully only by a management of production in terms of engineering ('Implementation I') any more.

The concept and design of the product also has to be transferred into the awareness of the client, i.e., the knowledge about the product has to be created together with the customers' mental activities by communication ('Implementation $I I$ '). The time lapse from a product idea until its realization and availability on the market has been shortened tremendously whereas in the meantime the communication of product design to the client basically remained the same. In terms of semiotic, as ever before, the customer has to get to know all dimensions of the product serving as a sign, i.e., on the syntactic, semantic and pragmatic levels. ${ }^{2}$ This 'diverse development of inter-time development of implementation I and II lead to a shift of their importance away from the implementation on the production side towards the implementation on the communication side' (Schmid 2001: 48).

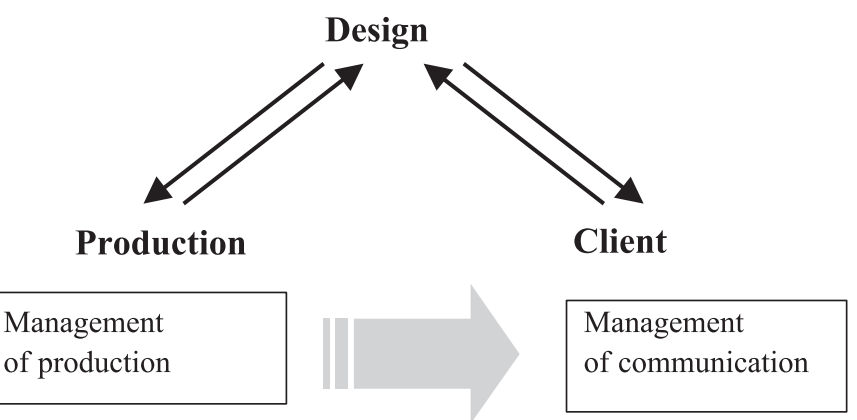

Figure 1. The shift of importance from production to communications (Schmid 2001: 48) 
This shift may lead to a turning point, putting the human factor of the intellectual capital in the center. It became obvious, especially in knowledge management, that focusing on IT-implementation by itself will not be a feasible solution for further developments with regard to the creation and distribution of knowledge in processes of communication (cf. Von Krogh et al. 2000: 12). With respect to the complexity of communication processes and culture, the IT-solution serves as a necessary foundation that makes the upper levels possible. Implementing a platform for a virtual community, for example, may serve as a medium for virtual communication of this community and give it an infrastructure, but the management of the community encompasses much more. To enhance intensive communication and promote the knowledge transfer, a community manager has to ensure a shared aim and establish a language within the community. The second level therefore has to refer to the communication processes and structures and aim at a so-called conversation management' (cf. Von Krogh et al. 2000: 121). Only by facilitating relationships and conversations can local knowledge be generated and shared across the organization. At a deeper level, this view 'relies on a new sense of emotional knowledge and care in the organization' (Von Krogh et al. 2000: 4) which builds up a communication culture including values and norms.

In all, Von Krogh et al. (2000: 4) stress the limitation of knowledge management itself in terms of overemphasizing information technology and measurement tools in the past. ${ }^{3}$ As a consequence, they propose the concept of 'knowledge enabling':

Knowledge enabling includes facilitating relationships and conversations as well as sharing local knowledge across an organization or beyond geographic and cultural borders. At a deeper level, however, it relies on a new sense of emotional knowledge and care in the organization, one that highlights how people treat each other and encourages creativity - even playfulness. (Von Krogh et al. 2000: 4)

Pointing out five enabling factors - knowledge vision, conversation management, mobilization of knowledge activists, context creation, and globalization of local knowledge - they suggest physical, face-to-face experiences as the key to conversion and transfer of tacit knowledge (cf. also Nonaka 1998: 46). As Nonaka puts it, 'through dialogue, an individual's mental models and skills are converted into common terms and concepts' (Nonaka 1998: 47). But is this conversion of mental models actually as easy as it appears? If language is one medium for the expression of one's observation about the world, and one's observations are required to 
create new knowledge (Von Krogh et al. 2000: 138), a company's language represents one of its most important assets (cf. Fiol 1991). If we refer to an organization as a system of a specific kind of interactive behavior, as a complex multifactorial system, the company's language and knowledge is a result of an ongoing process of semiosis of the individual actors (e.g., the employees). Therefore, an organization can be seen as semiotic constructs created and used by actors in continuous learning processes in interaction with their social and physical environment.

More points out the linkage from communication and organizational learning to knowledge management and argues that corresponding to the different levels of organizational learning from individual up to organizational level, it is necessary to deal ' $\ldots$ with the different communication processes and practices incorporated in these varied levels' (More 1998: 355-356). In discussing some categories of knowledge and organizations, she states that the critical aspect in these fields can mainly be traced back to the communication of knowledge '... in terms of interpersonal and collective organization practices ... meaning creation through dialogue and non-verbal cultural dimensions' (More 1998: 356). Therefore, it will be important to consider the pivotal point of 'communication as discourse or conversation' (More 1998: 357), i.e., emphasizing the relational dimensions among people and highlighting organizational understanding and knowledge as being produced and reproduced through discourse.

But with respect to the problem of knowledge sharing, knowledge transfer and even creation, one may notice that communication cannot be understood in terms of simple transferring knowledge in container metaphors in such a way that one only has to put his or her knowledge into it and send it to a receiver who has to unwrap it. Many communication models decorated with various metaphors can actually be attrributed to the classic sender-receiver model of Shannon and Weaver (1949). What is often forgotten is that their linear model only describes the technical process of transferring messages in general without reflections on the content or the effects of the messages, leaving out explanations about the complex phenomenon of communication.

According to More, what is missing from the current flurry is '... the vocabulary of communication ... in the field of knowledge management' (More 1998: 358) which may provide '... a richer grasp of intellectual capital and of knowledge management per se in contemporary and future organizational life' (More 1998: 359). But like Deetz (1997: 119) she only points out the importance without further substantial developments, e.g., how such a vocabulary might look or by giving any other solutions. 
Emanating from the outlined importance of conversation and language as one medium in particular as an essential component of knowledge creation it is worthwhile to take a look at some fundamentals that can be derived from communication theory. In the following section, as a starting point, I will propose to have a look at how knowledge can be characterized in semiotic terms describing it as signs. What are the characteristics of a sign that has the ability of transferring knowledge? Which levels of knowledge can be distinguished from the semiotic point of view? This micro perspective might give some basic insights which may influence further statements on macro perspectives.

\section{The implication of Leibniz's 'cognitio symbolica' theory}

Usually when we investigate knowledge management issues in an organization, we actually take a look at artifacts such as an Intranet or lessons learned databases, and behaviors such as team conversations or expert communication in order to create or 'exchange' knowledge. But neither the artifacts nor the behavior can represent the 'knowledge management system' itself. What is needed is a relation between artifacts and behavior to describe a more or less whole 'knowledge management system' of an organization. Such a relation is a representation, shared by a number of interacting actors. ${ }^{4}$ This representation gives both the artifacts and the behavior a meaning. A representation is therefore the result of the mental activity of an actor. In Leibniz's terms this mental activity can be described as 'cognition.' This term describes the process that leads to 'knowledge acquisition.' Because our knowledge of reality is necessarily a representational construction, the representational activity can be studied from a semiotic perspective, focusing on the meaning of behavior, i.e., the semiotic dimension of organizational behavior. The semiotic behavior is a sign-creating and sign-using one, always presupposing a 'something' that is represented through the sign. What is represented is what we can call the 'object,' which can be the world, an experience, or even an interaction. In the representational or semiotic process an object is related to a meaning through the sign. Signs can be viewed in different ways in semiotic theory:

According to Charles Morris (1971 [1938]), signs may describe the behaviorist view when seen as stimuli that generate specific responses. Secondly, understood as adaptive behavior from a biological-anthropological perspective, signs may also play an important role in the interaction of organisms with their environment (cf. Uexküll [1982]; Cassirer [1969]). A third perspective is the phenomenological one, where signs 
are regarded as being the building blocks of consciousness (cf. Husserl [1922]; Merleau-Ponty [1964]). A fourth approach might be the study of signs as cultural conventions. Here, language becomes the prototypical sign system. Signs convey messages and are used to share experiences within a community. Theoretical basis for this perspective can be found in Karl Bühler (1982 [1934]), Umberto Eco (1987) or Louis Hjelmslev (1961). Finally, signs may be viewed as cognition or knowledge. From this perspective of logic and epistemology, signs refer to a world, real and imagined, present and absent, concrete and abstract. Leibniz is a founding father of this approach. Although his theory, being written in Latin, suffers from difficulties impeding its reception, it is worth taking a look on it.

Gottfried Wilhelm Leibniz (1646-1716) was influenced by papers of Cavalieris, Descartes, Locke, Pascal and by meetings with Arnauld, Malebranche, Nicole and others. He can be placed between Descartes' rationalism (locating the beginning of cognition in mind) and Locke's empiricism (locating the matter in pure sensitive experience) whose tabula rasa formula 'nihil est in intellectu, quod non ante fuerit in sensu' (nothing is in mind which was not in sensual perception before) was added to by 'nisi ipse intellectus' (nothing except mind itself).

Leibniz is of value to gain insight into the process of knowledge acquisition from a semiotic point of view. In his 'Meditationes de Cognitione, Veritate, et Ideis' (Reflections on Knowledge, Truth, and Ideas), which clarifies his theory of knowledge, he tries to give a systematical characterization of the different kinds and levels of knowledge acquisition and its prerequisites. By starting with the genus 'cognitio,'5 which can be translated as 'knowledge' he describes the several species by means of a dichotomous classification reflecting the particular rank of perfection of knowledge. Judging from Leibniz's original plans for a universal language, Leibniz had a specific view about the nature of human cognitive processes, particularly about the nature of human reasoning. According to his view, knowledge is essentially symbolic: it takes place in a system of representations that possesses language-like structures. Indeed, Leibniz was one of the first to point out that all humans use certain signs in the knowledge acquisition process. Without signs it wouldn't be possible to even think of anything distinctly or reason about it.

To understand Leibniz's theory, one might start with reviewing the difference between 'res repraesentans' and 'res repraesentata.' In Leibniz's terms, 'res repraesentans' refers to a mental representation of a so-called 'oblatum.' ${ }^{6}$ By 'oblatum,' Leibniz suggests an entity or a self-produced idea of the knowledge-acquiring subject which therefore belongs to the sphere of 'notio' (knowledge). 


\section{Terms of Mind}

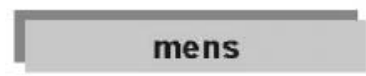

\section{res repraesentans}

\section{Terms of World}

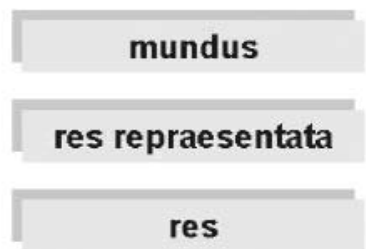

Figure 2. Overview of central terms belonging to 'mens' (mind) and 'mundus' (world)

The objects to be acquired in the process of knowledge acquisition are called 'res repraesentata,' which therefore are outside the sphere of 'notio' but belonging to the sphere of world ('mundus'). In an ideal case, a 'notio' is composed of several known and distinguishable elements called 'notae' which themselves can be subdivided into 'notarum notae.'

Leibniz starts with a description of certain levels of knowledge to be distinguished by the criteria of recognizing the elements of the 'res repraesentata.'

The lowermost level of knowledge is called 'notio obscura.' On this level of least perfect perception, one cannot recognize the 'res repraesen-

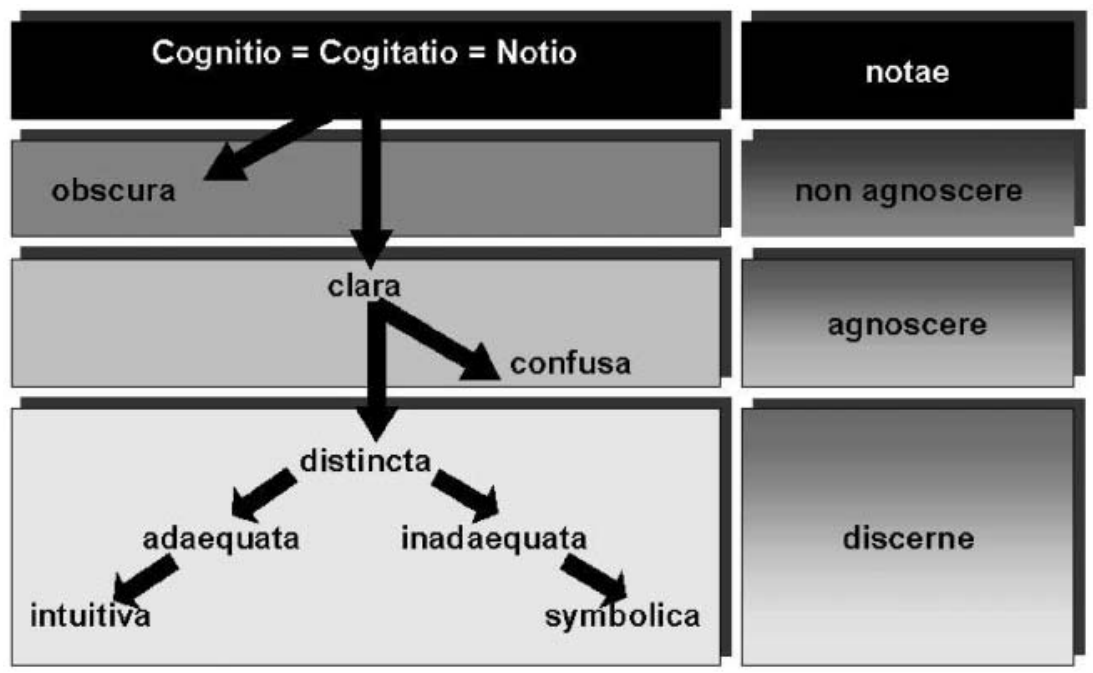

Figure 3. Leibniz's hierarchy of cognition/knowledge levels 
tata.' No identification or differentiation can be made from other 'res repraesentata.' Only the existing 'oblatum' in our 'mens' as a 'res repraesentans' is present and releases the process of knowledge acquisition ('non agnoscere') 'Obscura est notio quae non sufficit ad rem repraesentatam agnoscendam ...' (Leibniz 1965 [1684]: 422). But though addressing the object to be recognized, the process remains in searching for criteria to differentiate. For this level, Leibniz mentions the cognition of a once-seen flower or an animal that is only vaguely or obscurely recognized. We cannot identify or perceive these objects correctly; our perception of them is quite cloudy. Usually, we are not even conscious of the occurrence of the objects.

At the level of the 'cognitio clara,' the 'res repraesentata' are ascertainable ('agnoscere') and can be identified from others. At this level, Leibniz makes a distinction between a 'cognitio confusa' and a 'notio distincta' by using the criteria of communicability of the 'notae' (Leibniz 1965 [1684]: 422).

A 'cognitio confusa' cannot distinguish between the necessary 'notae' of the 'res repraesentata' by which it defines itself. The identification of the 'res repraesentata' is only possible by simple sensory perception but cannot be communicated explicitly or discriminated analytically. For this category, Leibniz gives the example of having a certain kind of knowledge on perfumes or colors: 'ita colores, odores, sapores, aliaque peculiaria sensuum objecta satis clare quidem agnoscimus et a se invicem discernimus, sed simplici sensuum testimonio, non vero notis enuntiabilibus ...' (Leibniz 1965 [1684]: 422). To recognize them depends mainly on sensory presentation in direct perceptions or in remembrance. For transferring this kind of knowledge, it would be necessary to share the same presence of a context. An important precondition is that the actor has to be copresent in the concrete situation, as no name yet exists; no transfer via signs is possible. We will come back to this kind of knowledge when drawing parallels to what today is called 'tacit knowledge' (Polanyi 1966).

At the next step, a 'notio distincta' can identify the 'notae' of the 'res repraesentata' as well as communicate them ('discerne'). But the act of communication of the 'notae' is not an essential precondition of a 'notio distincta' which therefore can also only be carried out mentally. The 'notio distincta' encompasses five further levels, one to be characterized as a special case (Leibniz 1965 [1684]: 423).

To start with this special case, the simplest cognition is called 'notio primitiva,' which can be characterized by three points: 'nota sui ipsius,' 'irresolubilis,' and 'per se intelligere.' This definition encompasses three features. First, the 'notio primitiva' does not consist of any further 'notae' and therefore is the nota itself ('nota sui ipsius'). Second, from this it 
follows that this nota cannot be subdivided (or 'dissolved') in any further 'notae' because it is not composed of other 'notae' ('irresolubilis'). Third, if the nota itself is the only characteristic; it can only be understood through this one and only nota itself ('per se intelligere'). With this special case Leibniz points out the theoretical possibility of knowledge which is not composed of various characteristic elements (notae) but represents itself 'through itself.' Leibniz himself points out that he can scarcely imagine an example of such a kind of 'notio primitiva,' but for the completeness of the dimensions it is important to integrate this case. At the level of the 'cognitio inadaequata,' the 'notae' of the 'notae' (the so-called 'notarum notae') cannot be recognized precisely. Here, one can only precisely recognize of which elements the knowledge is composed, but the elements themselves cannot be subdivided into their 'notarum notae' and therefore cannot be explained in further detail. Leibniz called this kind of knowledge 'inappropriate.'

If this distinction and identification of the 'notarum notae' is possible, nothing confusing is left and the ideal case of a "cognitio adaequata" is reached. For this most perfect perception, endowed with reflexive power and acts of reflections, all knowledge elements including the distinction and explanation of the elements are possible ('seu cum analysis ad finem usque producta habetur, cognition est adaequata') (Leibniz 1965 [1684]: 423).

One further step beyond this ideal case is called 'cognitio intuitiva,' which is characterized by a realization of all 'notae' not only distinct, but at the same time. For this case, only a 'notio primitiva' can serve as a 'cognitio intuitiva.' In all of the other cases, a realization of all 'notae' and 'notarum notae' of a complex cognition of knowledge cannot be made at the same time but only in a process in time.

In this knowledge cognition process, Leibniz points out the simple statement that we use signs instead of the objects. While doing so, we do not explain each sign with its elements explicitly because we think that this explanation is not necessary. Proceeding on the assumption that the explication would be possible if necessary, we operate with mental entities in our minds. The exact explications and meanings of these mental entities often remain dark in our mind. This level of cognition is called 'cogitatio symbolica' or, as a synonym, 'cogitatio caeca' ('qualem cogitationem caecam vel etiam symbolicam appellare soleo, qua et in Algebra et in Arithmetica utimur, imo fere ubique') (Leibniz 1965 [1684]: 423). Leibniz refers to the term 'blind' ('caeca') because an explicit explication of the words used as signs would lead to an infinite recourse, which would mean that the explicated signs itself would have to be explicated, too. Therefore, one disclaims an explication of each 'notae' and supposes that the words are understood at least approximately. Herein one reason can be seen 
why, above all in the so-called 'symbolic cognition,' contradictions often remain undiscovered. Therefore, the level of 'cogitatio symbolica' can be characterized, in the Leibnitzian sense as a clear, distinct, and inadaequate cognition (see figure 2). The knowledge as described here represents a selfreferential system that is open to the world only through processes of communication, explication and thereby continuous constructing and restructuring.

Summing up, we can find a precise distinction of knowledge-levels in Leibniz's hierarchy of cognition. Starting from the perspective of knowledge as a process of semiosis, which we found as an ongoing process of cognition and interpretation of signs, we can easily become aware of the limitations of knowledge explications through communication. This is because all elements of knowledge have to be explained through communication, i.e., through communicating sings as well, in order to reach understanding.

This perspective is highly interesting because it draws our attention to a basic human experience: the experience that the reality we live in is always a mediated or semiotic reality with the sign as the starting point for our explorations. From this approach we assume that signs necessarily mediate between data and knowledge. Data is not directly accessible or known directly, but has to be translated into information by use of signs. Therefore, the relevance of taking a closer look at signs becomes quite obvious, for the processes of communication within an organization as well as for external communication with customers and other stakeholders. The pivotal point in knowledge transfer to employees and customers will be the effective influence of the 'actors' by use of signs, i.e., giving them the right 'hints' to create understanding. If symbols form the basis of understanding, it is these representations that form the basis for all situation assessment and decision-making. From this point, it will be of great importance to establish a well-defined set of formal rules for syntax, semantics, and pragmatics. These present set of symbols will then be used as a basis for developing shared representations, building the foundation for any future shared virtual environments, as we also can learn from Jakobson (1960) or Gumperz (1982) with their references to shared meaning systems or codes. Gumperz shows that there exists a general mechanism consisting of a bunch of communicative and interpretative or 'inferential' codes that are not to be understood as a fixed set of signs, but as contrasting ways to contextually organize the cognitive complexity into diverse sets of communicative signals. These codes are inherently interpretative and loose. They precede language, emerging from semantic representations including referential and prepositional contents like shared knowledge, dispositions, etc. In this sense, a code is an abstract formulation 
and construction about the relationship between an observable sign and the interpretation of a sign.

One point of attachment concerning the knowledge creation processes of employees, customers or other stakeholder groups might be the creation of a distinct language of the organization, explaining as many constituting elements as possible and offering opportunities to create codes to better understand them. Furthermore, the central issue in knowledge acquisition will be how to detect different forms of knowledge to foster innovation and how to deal with them, e.g., tacit knowledge which depends on sensory perception only and therefore requires the use of senses (cf. 'cognitio confusa'). This process could be supported with what Gumperz (1982) called 'contextualization cues' like paralinguistics, prosodics, kinesics or nonverbal elements through each actor in the particular concrete situation. However, as shown as a starting point above, Leibniz's theory of knowledge can contribute deep insights to the knowledge management debate, pointing out its chances and limitations.

\section{Outlook: The relevance of Leibniz's theory for communication and knowledge}

Although Leibniz's theory of 'cogitatio symbolica' does not refer to interaction processes between individuals explicitly, his systematic is of high relevance for the process of human communication and can be transferred to the knowledge acquisition process. He specifically describes a basic principle of how individuals interact with each other by use of symbols and how this act of explanation can lead to misunderstandings. The meaning of the used symbols always remains implicit and 'dark' in the sense that the level of symbols cannot be transcended and has no access to the 'res' itself. Even a paraphrase of the understood information as a control means of understanding would itself again have to refer to symbols. These symbols again would have to be explicated and so on, leading to the same problem of verification like at the beginning.

While communicating our knowledge we often suppose our partner's understanding of our signs and proceed until the moment when a misunderstanding becomes obvious. One of the reasons for communication failure in interpersonal communication of knowledge transfer therefore can be seen in the missing or belated explication of the entities and meaning to which we refer. As we have seen, only on the last level of 'cognitio adaequata' are we actually able to explicate our knowledge precisely and decompose the elements of which it consists. Paradoxically, this phenomenon can scarcely be overcome. Concerning the paradox of increasing 
explicity, it is the strong will of explicating knowledge that leads to the inefficiency of its explication.

Moreover, within Leibniz's theory we can find an exact hierarchy of the various levels of knowledge and how human cognitive processes follow determinable axioms of logic to gain knowledge. Three centuries later, we can find similar ideas of distinguishing what today's popular theories call 'tacit' and 'explicit' knowledge. While tacit knowledge is difficult to capture, codify, adopt, and distribute because individuals cannot articulate this type of knowledge, explicit knowledge seems easy to articulate, to capture, and to distribute in different formats (Polanyi 1966). Tacit knowledge can be compared to what Leibniz analyzed as dark or confused knowledge. It can be described as a state of affairs, which is similar to a remembered state of affairs and therefore always depends on the context. Often, it cannot be coded, but has to be experienced. Sharing this kind of knowledge is only possible for those who are copresent. According to Polanyi (1966: 16), in each activity there are two mutually exclusive, different levels or dimensions of knowledge: Knowledge about the object or phenomenon that is in focus - 'focal knowledge,' which can be compared to artifacts. The knowledge that is used as a tool to handle or improve what is in focus is called tacit knowledge and can also be compared to the behavioral side. According to Polanyi, the focal and tacit dimensions are complementary. The tacit knowledge functions as a background knowledge that assists in accomplishing a task that is in focus. Both dimensions are important in the process of knowledge creation. In a semiotic process, an object is related to a meaning with the help of signs. As long as our perception of the world is unproblematic, we tend to assume that our representations match the world. It is sometimes difficult to become aware, above all in homogenous teams, of the underlying presumptions of a common sense world in which all members obviously share a similar cognitive style. Finally, these presumptions can lead to a lack of explanations for the single elements of knowledge in the knowledge creation and transfer process. However, when the representation becomes ambiguous, because more than one representation is possible, and different representations seem to contradict each other, then representation and reality part ways, and new representations have to be constructed. To support the process of knowledge creation, it might be important to enable knowledge communication processes within an interdisciplinary team. Here, the chance of different cognitive styles leading to different representation mechanisms may be higher than in homogenous teams. In externalization processes, the ambiguity might be resolved by decomposing knowledge into its elements as far as possible, always reflecting the difficulties in doing so. 
To conclude, if one acknowledges that knowledge consists of representations, and these representations are of unique importance in decision systems within organizations, it becomes obvious that the management of an organization basically consists of knowledge management. For the management therefore it might be of great importance to gain a basic notion of the epistemological perspectives on the various levels of how to 'manage representations.' The theory provides us with insights into how to deal with different forms and levels of knowledge, as for example tacit or 'confused' knowledge has to be experienced, while 'distinct' knowledge can be analyzed into further details and communicated upon. Also, when referring to the constantly growing environmental complexity we might become aware of the challenge of growing interpretations of representations organizations are facing. Realizing these challenges, developing new concepts and combining old concepts of managing them will be an important step in the right direction. This paper has given a first insight in it.

\section{Notes}

1. By 'semiosis' I mean ... an action, or influence, which is, or involves, a cooperation of three subjects, such as the sign, its object, and its interpretant, this tri-relative influence not being in any way resolvable into actions between pairs" (EP 2 1998: 441). In other words, Peirce refers to an ongoing, dynamic and infinite process of interpreting signs by referring to other signs (Moore 1972).

2. The differentiation between syntax, semantic, and pragmatic as the three dimensions of semiotic can be traced back to Morris (1971 [1938]). He defines syntax as the relation of signs among each other to form rules of combination, semantic as the relation of signs and their 'designats' (objects) and pragmatic as the relation between signs and their 'interprets' ('living organisms').

3. However, a turning point in knowledge management debates can be derived from the recently growing theories doubting or even denying the possibility of actually managing knowledge (Baecker [1999]; von Krogh et al. [2000]; Martensson [2000]; Maula [2000]).

4. Of course this does not imply that all actors involved must represent a knowledge management system in the same way or in one way only. But, if the knowledge management system should be effective, the involving actors should at least share a representation of their behavior.

5. 'Cognitio,' 'Cogitatio,' and 'Notio' are synonyms in Leibniz's theory (cf. Ungeheuer 1990: 502).

6. One translation for 'oblatum' could be 'idea' or 'imagination.'

\section{References}

Baecker, Dirk (1999). Organisation als System. Frankfurt a. Main: Suhrkamp.

Bühler, Karl (1982 [1934]). Sprachtheorie. Die Darstellungsfunktion der Sprache. Stuttgart/ New York: Fischer. 
Cassirer, Ernst A. (1969). Wesen und Wirkung des Symbolbegriffs. Darmstadt: Wissenschaftliche Buchgesellschaft.

Deetz, Stanley (1997). Communication in the age of negotiation. Journal of Communication 47 (4), 119-135.

Eco, Umberto (1987). Semiotik: Entwurf einer Theorie der Zeichen. Munich: Fink.

Etzioni, Amitai and Etzioni, Oren (1999). Face-to-face and computer-mediated communities. A comparative analysis. Information Society 15 (4), 241-248.

Fiol, C. Marlena (1991). Managing cultures as a competitive resource: An identity-based view of sustainable competitive advantage. Journal of Management 17 (1), 191-211.

Gumperz, John J. (1982). Discourse Strategies. Cambridge: Cambridge University Press.

Hjelmslev, Louis (1961). Prolegomena to a Theory of Language. Madison: University of Wisconsin Press.

Husserl, Edmund (1922). Logische Untersuchungen. Halle: Niemeyer.

Jakobson, Roman (1960). Closing statement: Linguistics and poetics. In Style in Language, Thomas A. Sebeok (ed.), 350-377. Cambridge, MA: MIT Press.

Leibniz, Gottfried W. (1965 [1684]). Meditationes de cognitione, veritate, et ideis. In Die philosophischen Schriften von Gottfried Wilhelm Leibniz, vol. 4, Carl Immanuel Gerhardt (ed.), 422-426. Die philosophischen Schriften first published 1880. Reprint, Hildesheim: Olds.

Luhmann, Niklas (1991). Social Systems. Palo Alto: Stanford University Press.

Martensson, Maria (2000). A critical review of knowledge management as a management tool. Journal of Knowledge Management 4 (3), 204-216.

Maturana, Humberto R. and Varela, Francisco J. (1992). The Tree of Knowledge: The Biological Roots of Human Understanding. Boston: Shambhala Publications.

Maula, Marjatta (2000). The sense and memory of a firm - implications of autopoiesis theory for knowledge management. Journal of Knowledge Management 4 (2), 157-161.

McDermott, Richard (1999). How information technology inspired, but cannot deliver knowledge management. California Management Review 41 (4), 103-117.

Meredith, Rob and Burstein, Frada V. (2001). Getting the message across with communicative knowledge management. In Proceedings of the Australian Conference on Knowledge Management and Decision Support (ACKMIDS'2000), 43-55. Melbourne: Australian Scholarly Publishers.

Merleau-Ponty, Maurice (1964). Signs. Evanston, IL: Northwestern University Press.

Moore, Edward C. (1972). Charles S. Peirce: The Essential Writings. New York: Harper Row.

More, E. (1998). The role of communication in current debates on knowledge management. Journal of Communication Management 3 (4), 353-361.

Morris, Charles W. (1971 [1938]). Foundations of the theory of signs. In Writings on the General Theory of Signs, 13-71. The Hague: Mouton.

Nonaka, Ikujiro (1998). The concept of 'Ba': Building a foundation for knowledge creation. California Management Review 40 (3), 40-54.

Nonaka, Ikujiro and Takeuchi, Hirotaka (1995). The Knowledge-Creating Company - How Japanese Companies Create the Dynamics of Innovation. New York: Oxford University Press.

Peirce, Charles S. (1931-1966). The Collected Papers of Charles S. Peirce, 8 vols., C. Hartshorne, P. Weiss, and A. W. Burks (eds.). Cambridge: Harvard University Press. [Reference to Peirce's papers will be designated $C P$ followed by volume and paragraph number.]

—(1998). Essential Peirce. Selected Philosophial Writings, vol. 2 (1893-1913), Peirce Edition Project (eds.). Bloomington: Indiana University Press. [Reference to Volume 2 of Essential Peirce will be designated EP 2.] 
Pfeffer, Jeffrey and Sutton, Robert I. (1999). Knowing 'what' to do is not enough: Turning knowledge into action. California Management Review 42 (1), 83-108.

Polanyi, Michael (1966). The Tacit Dimension. London: Routledge.

Schmid, Beat F. (2001). What is new about the digital economy? EM - Electronic Markets, The International Journal of Electronic Commerce and Business Media 11 (1), 44-51.

Shannon, Claude E. and Weaver, Warren (1949). The Mathematical Theory of Communication. Urbana, IL: University of Illinois Press.

Steffe, Leslie P. and Thompson, Patrick W. (eds.) (2000). Radical Constructivism in Action: Building on the Pioneering Work of Ernst Von Glasersfeld. London: Routledge Falmer Press.

Straub, Detmar and Karahanna, Elena (1998). Knowledge worker communications and recipient availability: Toward a task closure explanation of media choice. Organization Science 9 (2), 160-175.

Uexküll, Jakob von (1982). The theory of meaning. Semiotica 42 (1), 25-82.

Ungeheuer, Gerold (1990). Die 'cognitio symbolica' bei Leibniz. In Kommunikationstheoretische Schriften II: Symbolische Erkenntnis und Kommunikation, vol. 15, Heinrich Walter Schmitz (ed.), 493-524. Aachen: Alano Rader.

Von Krogh, Georg, Kazuo, Ichijo and Nonaka, Ikujiro (2000). Enabling Knowledge Creation. How to Unlock the Mystery of Tacit Knowledge and Release the Power of Innovation. New York: Oxford University Press.

Webber, Alan (1993). What's so new about the new economy? Harvard Business Review January/February, 24-42.

Wilkesmann, Uwe (2000). Die Anforderungen an die interne Unternehmenskommunikation in neuen Organisationskonzepten. Publizistik 45 (4), 476-495.

Diana Ingenhoff (b. 1971) is an Associate Professor for Media and Communication Science at the University of Fribourg〈diana.ingenhoff@unifr.ch〉. Her research interests include organizational communication, semiotics, issues and reputation management, and knowledge communication. Her major publications include Issues Management in Multinational Corporations (2004); and 'Trust through reputation — basic model and empirical evidence in e-business' (2005, with S. Einwiller and A. Herrmann). 